\title{
Publisher Correction: A computational reward learning account of social media engagement
}

\author{
Björn Lindström (1), Martin Bellander (1), David T. Schultner, Allen Chang, Philippe N. Tobler \& David M. Amodio
}

Correction to: Nature Communications https://doi.org/10.1038/s41467-020-19607-x, published online 26 February 2021.

The original version of this Article was updated shortly after publication, because the Reporting summary file was incorrect. The error has now been fixed and the Reporting summary PDF is available to download from the HTML version of the Article.

The original version of this Article contained errors in the Data availability statement, which read:

"The data for Study 1 are available from ref. 30. Data for Study 2 and Study 3 are available at the Open Science Framework (osf.io/ $765 \mathrm{py} /$ ). A reporting summary for this article is available as a Supplementary Information file. Source data are provided with this paper".

The corrected version states:

The availability of the dataset analyzed in Study 1 is described in Ferrara, E., Interdonato, R. \& Tagarelli, A. Online popularity and topical interests through the lens of instagram. In Proc. 25th ACM Conference on Hypertext and Social Media-HT'14, 24-34 (ACM Press, 2014).

The datasets analyzed in Study 2 are available on reasonable request from the corresponding author. The dataset analyzed in Study 3 is available on the Open Science Framework (https://osf.io/765py/). A Reporting summary for this article is available as a Supplementary information file. Source data are provided with this paper".

This has been corrected in both the PDF and HTML versions of the Article.

Published online: 16 March 2021

\footnotetext{
(c) (i) Open Access This article is licensed under a Creative Commons Attribution 4.0 International License, which permits use, sharing, adaptation, distribution and reproduction in any medium or format, as long as you give appropriate credit to the original author(s) and the source, provide a link to the Creative Commons license, and indicate if changes were made. The images or other third party material in this article are included in the article's Creative Commons license, unless indicated otherwise in a credit line to the material. If material is not included in the article's Creative Commons license and your intended use is not permitted by statutory regulation or exceeds the permitted use, you will need to obtain permission directly from the copyright holder. To view a copy of this license, visit http://creativecommons.org/licenses/by/4.0/.
}

(c) The Author(s) 2021 